\title{
EFFECTS OF $n$-BUTANOL AND FILIPIN ON MEMBRANE PERMEABILITY OF DEVELOPING WHEAT ENDOSPERMS WITH DIFFERENT STEROL PHENOTYPES
}

\author{
Pilar CARBONERO, J. V. TORRES and F. GARCIA-OLMEDO \\ Departamento de Bioquimica, E. T.S. Ingenieros Agrónomos, Madrid-3, Spain
}

\section{Introduction}

Sterols are considered structural components of higher plant membranes on the basis of their presence in membrane-containing subcellular fractions [1-3], their effect on plant membrane permeability when added exogenously $[4,5]$ and the serisitivity of plant cells to the polyene antibiotic filipin [6-8], which action is known to depend on the presence of sterols in the membrane (see [8]).

Our recent finding of a gene that controls the free sterol level of developing wheat endosperm [9-11] allows to investigate whether endogenous sterol modifies membrane permeability in the same way as that added externally. We report here on the effect of $n$-butanol and filipin on the leakage properties of developing wheat endosperms with different genetically determined free sterol levels.

\section{Material and methods}

Triticum aestivum $\mathrm{L}$. cultivars Candeal and Mara and $T$. durum Desf. cultivar Senatore Capelli were grown in an open field. The approximate anthesis dates were tagged in each spike. Spikes were collected at different dates and equal weight lots of eight kernels each were made. Endosperms were dissected by hand, cut in four pieces, and placed in $50 \mathrm{ml}$ of $0.1 \mathrm{M}$ phosphate buffer, $\mathrm{pH} 6.0,0.1 \mathrm{M}$ sucrose, for $16 \mathrm{~h}$ at $15^{\circ} \mathrm{C}$. Then, they were transferred to the incubation mixtures which consisted of $5 \mathrm{ml}$ of the same buffer with $n$-butanol (2\% or $5 \%$ ) or with filipin $(50 \mu \mathrm{g} / \mathrm{ml}$ or $100 \mu \mathrm{g} / \mathrm{ml})$. Filipin U.5956 (crystalline complex), $66 \%$ pure, was kindly donated by Dr G. B. Whitefield, the Upjohn
Co., Kalamazoo, Michigan, USA. It was added to the incubation mixture as a concentrated methanolic solution. The final methanol level in all tubes containing filipin was $1 \%$. Leakage in appropriate control samples incubated in buffer with and without $1 \%$ methanol did not differ significantly during the observation period. Incubations were carried out at $25^{\circ} \mathrm{C}$ for up to $6 \mathrm{hr}$. u.v. Spectra $(220-400 \mathrm{~nm})$ were obtained after filtration through a Whatman GF/C filter, using a $10 \mathrm{ml}$ Luer lock syringe and a Millipore filter holder. The samples were returned to the incubation mixture when necessary. Efflux of intracellular material was measured by the absorbance at $260 \mathrm{~nm}$. When filipin was present, absorbance at $355 \mathrm{~nm}$ was measured to follow its uptake by the tissue and to correct for the decrease in $260 \mathrm{~nm}$ absorbance due to this phenomenon. u.v. Spectra of different concentrations of filipin with or without added sterols (cholesterol, Merck; $\beta$-sitosterol, Serva) were obtained to check for possible changes during the observation period and to correct for deviations from LambertBeer's law. Differences between duplicates were within $7 \%$ in all cases.

One tot of hand dissected endosperms from each stage was freeze dried and the free and esterified sterols determined as previously described [10].

\section{3, Results}

As shown in fig. 1, cultivars S. Capelli (T. durum) and Mara ( $T$. aestivum) are characterized by a low level of steryl palmitate and a high level of free sterol (L phenotype [10,11]) and cultivar Candeal ( $T$. aestivum) has high steryl palmitate and low free sterol (PL phenotype). 


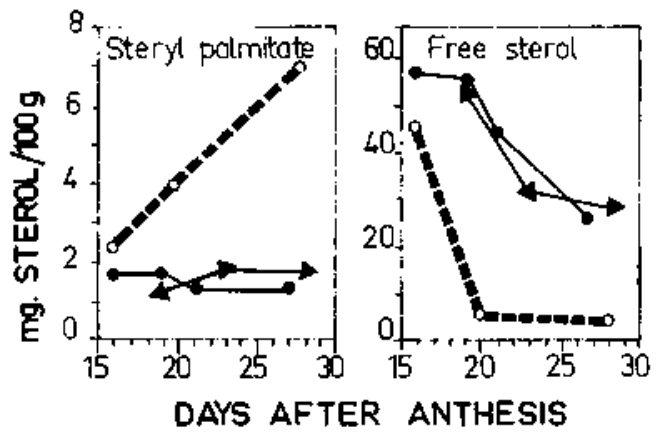

Fig.1. Evolution of steryl palmitate and free sterol during development of wheat endosperms with PL and $\mathrm{L}$ phenotypes. (o): $T$, aestivum cv. Candeal, PL; (^): $T$. aestivum cv. Mara, L; (๑): $T$, durum cv. Senatore Capelli, L.

The time course of leakage induced by $n$-butanol and by filipin in $\mathbf{S}$. Capelli endosperm at 15 days after anthesis is represented in fig. 2 .

In fig. 3., the decrease of absorbance at $355 \mathrm{~nm}$, which measures uptake of filipin by the tissue, is plotted versus time. Practically the same uptake kinetics were observed in all samples and there were no significant differences between $L$ and $P L$ pheno types.

The evolution of leakage stimulation by $n$-butanol $(5 \%)$ and by filipin $(100 \mu \mathrm{g} / \mathrm{ml})$ during development is represented in fig. 4 . Endosperms could not be dissected without damage beyond $27-28$ days after anthesis.

Endosperms from the three cultivars collected at 27-28 days after anthesis were exposed to two levels

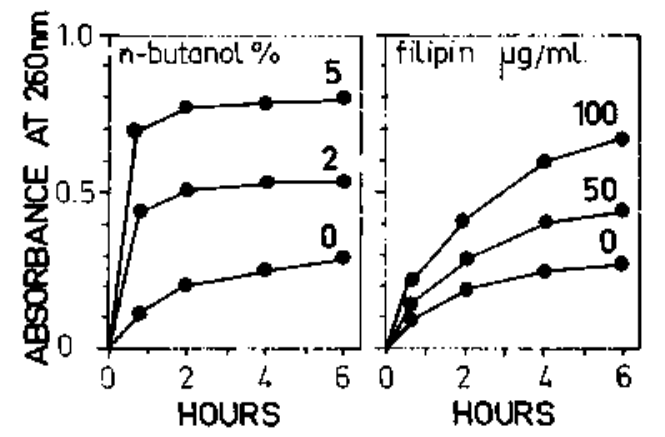

Fig.2. Efflux of materials absorbing at $260 \mathrm{~nm}$ from Senatore Capelli endosperm at 15 days after anthesis, exposed to $n$ butanol and to filipin.

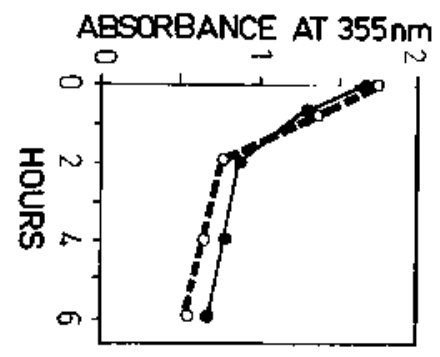

Fig.3. Time course of filipin uptake by endosperms with PL and $\mathbf{L}$ phenotypes. (o): Candeal, PL; (•): Senatore Capelli, L.

of $n$-butanol (fig.4). At $2 \% n$-butanol, leakage of the two L phenotype cultivars was only slightly stimulated, while in the PL phenotype the stimulation was similar to that at $5 \% n$-butanol.

Samples taken at the above stage were also exposed to filipin $(100 \mu \mathrm{g} / \mathrm{ml})$ in the presence of cholesterol $(100 \mu \mathrm{M})$ and $\beta$-sitosterol $(100 \mu \mathrm{M})$. Leakage data are summarized in table 1 . Cholesterol inhibits the effect of filipin more effectively than $\beta$-sitosterol. In both cases, the degree of inhibition is inversely related to the sensitivity of the endosperm.

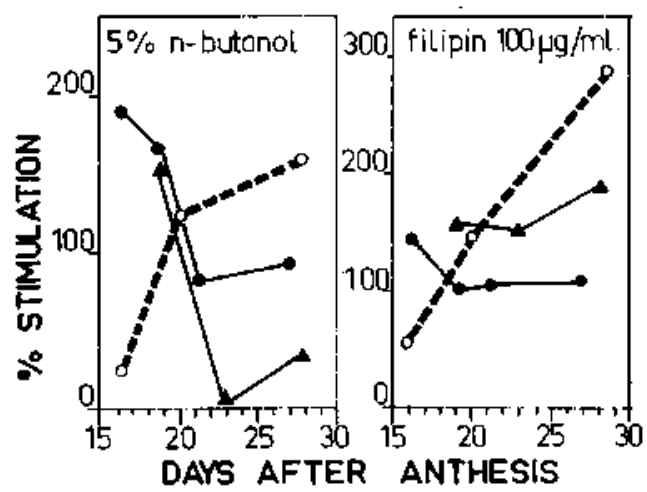

Fig.4. Evolution of leakage stimulation by $n$-butanol and by filipin in developing wheat endosperms with $\mathrm{PL}$ and $\mathrm{L}$ phenotypes. Stimulation is expressed as percentage of leakage increase at $5 \mathrm{hr}$ incubation over control samples, exposed to buffer only in the case of $n$-butanol, or to buffer with $1 \%$ methanol in the case of filipin. (o): Candeal, PLi (४): Mara, L; (৫): Senatore Capelli, L. 
Table 1

Inhibition by added sterol of the filipin effect in endosperms with PL and $L$ phenotypes collected at $27-28$ days after anthesis

\begin{tabular}{lccc}
\hline & \multicolumn{3}{c}{ \%Leakage Stimulation } \\
\cline { 2 - 4 } Additions & Candeal (PL) & Mara (L) & S. Capelli (L) \\
\hline Filipin $(100 \mu \mathrm{g} / \mathrm{ml})$ & 287 & 238 & 117 \\
Cholesterol $(100 \mu \mathrm{M})$ & 0 & 8 & 9 \\
$\beta$-Sitosterol $(100 \mu \mathrm{M})$ & 24 & 19 & 23 \\
Filipin $(100 \mu \mathrm{g} / \mathrm{ml})+$ cholesterol $(100 \mu \mathrm{M})$ & $63(79)^{\mathrm{a}}$ & $114(52)$ & $71(39)$ \\
Filipin $(100 \mu \mathrm{g} / \mathrm{ml})+\beta$-sitosterol $(100 \mu \mathrm{M})$ & $151(48)$ & $137(42)$ & $110(6)$ \\
\hline
\end{tabular}

a Figures in parenthesis express percentage inhibition of filipin effect by added sterol.

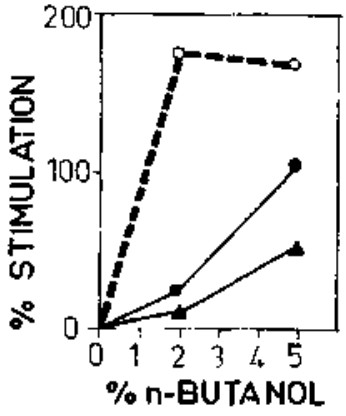

Fig.5. Leakage stimulation by two levels of $n$-butanol in endosperms with $P L$ and $L$ phenotypes collected at 27-28 days after anthesis. (o): Candeal, PL; (^): Mara, L.; (๑): Senatore Capelli, $\mathbf{L}$.

\section{Discussion}

Grunwald [4] has shown that alcohols stimulate the efflux of intracellular material in Beta vulgaris root cells and that added sterols can inhibit this effect. He has further established that a free $\mathrm{C}_{3}$ hydroxyl group, at least one double bond, and a relatively flat configuration are requirements for the membrane activity and, specifically, that sterol esters and glycosides are inactive $[5,12]$. A comparison of the activity of cholesterol, campersterol, stigmasterol and $\beta$-sitosterol seems to indicate that it decreases as the bulkiness of the $C_{17}$ side chain increases [12].

The genetic variants used in our study differ markedly in their free sterol level (fig.1). It has been previously shown that the free sterol per endosperm or per cell increases in the $L$ phenotype during the cell enlargement phase of endosperm development, which starts 16-19 days after anthesis, and decreases sharply in the PL phenotype. This difference is the result of an increased net esterification in the latter which affects the four main 4-demethyl sterols, namely $\beta$-sitosterol, stigmasterol, cholesterol and campesterol [11].

In Candeal (PL phenotype), sensitivity to $n$-butanol increases as the free sterol per cell decreases and in the $L$ phenotype (Mara and $S$. Capelli) sensitivity decreases as free sterol per cell increases. These data and those in fig. 5 are consistent with an inhibitory effect of endogenous sterol on n-butanol induced leakage.

Mudd and Kleinschmidt [6] have demonstrated that efflux of intracellular material from Solanum tuberosum and Beta vulgaris discs is also stimulated by filipin. In these cases, as in ours, filipin is initially uptaken by the tissue at a rapid rate and subsequently at a slower one (fig.3). At least two processes seem to be involved [6]. If the first one is tissue penetration the slower action of filipin versus $n$-butanol (fig. 2 ) could be explained in terms of a faster penetration by the latter.

Hendrix and Higinbotham [8] have reported that exogenous cholesterol reverses the filipin effect on $\mathrm{K}^{+}$and $\mathrm{NO}_{3}^{-}$uptake by stem cells of Pisum sativum. Similar reversals of filipin actions by free sterols have been observed in fungi [13]. In the first case, it could not be excluded that the reversal was due to the interaction sterol-polyene in the outer solution and not in the membrane [8]. The fact that the evolution of filipin sensitivity during endosperm development in 
$\mathrm{L}$ and PL phenotypes follows a pattern similar to that of $n$-butanol sensitivity (fig.4) lends support to the idea that the main effect of free sterol in the membrane is to impart stability [8].

Added cholesterol is more effective than $\beta$-sitosterol in the inhibition of the filipin effect (table 1), which is in accord with the previous observation by Grunwald [5] and with their relative ability to enter liposomes and ery throcyte membranes [14]. The inverse rela. tionship between the magnitude of the filipin effect and the degree of its reversal by added sterol can be interpreted as a complementation between endogenous and exogenous sterol in membrane stabilization.

\section{References}

[1] Kemp, R. J, and Mercer, E. I. (1968) Biochem. J. 110, 119-125.
[2] Grunwald, C. (1970) Plant Physiol. 45, 663-666.

[3] Brandt, R. D, and Benveniste, P. (1972) Biochim. Biophys. Acta 282, 85-92.

[4] Grunwald, C. (1968) Plant Physiol. 43, 484-488.

[5] Grunwald, C. (1971) Plant Physiol. 48, 653-655.

[6] Mudd, J. B. and Kleinschmidt, M. G. (1970) Plant Physiol, 45, 517-518.

[7] Maretzki, A. and Thom, M. (1972) Ptant Physiol. 49, $177-182$

[8] Hendrix, D. L. and Higinbotham (1973) Plant Physiol. 52, 93-97.

[9] García-Olmedo, F. (1968) Nature 220, 1144-1145.

[10] Torres, J. V. and Garcia-Olmedo, F. (1974) Plant Sci. Letters 3, 213-217.

[11] Torres, J. V. and García-Olmedo, F., unpublished.

[12] Grunwald, C. (1974) Plant Physiol. 54, 624-628.

[13] Gottlieb, D., Carter, H. E., Wu, L. C. and Sloneker, J. H. (1960) Phytopathology 50, 594-603.

[14] Edwards, P. A. and Green, C. (1972) FEBS Lett. 20, 97-99. 